All letters are subject to editing and may be shortened. Letters should be sent to the BJGP office by e-mail in the first instance, addressed to

journal@rcgp.org.uk (please include your postal address). Alternatively, they may be sent by post as an MS Word or plain text version on CD or DVD. We regret that we cannot notify authors regarding publication. Letters not published in the Journal may be posted online on our Discussion Forum. For instructions please visit: http://www.rcgp.org.uk/bjgp-discuss

\section{HIV testing}

I could not agree more with the sentiments of Barber et al, in their letter published in the May edition of the BJGP. ${ }^{1}$ I do, however, wish to add in a couple of points, which I hope readers will find interesting and add to the ongoing debate $e^{2,3}$ of how to uncover the $27 \%$ of people with unidentified HIV infection in the UK.

Firstly, if general practice is really serious about contributing to the reduction in those with HIV infection, we need to enhance testing and ensure that the primary and secondary care sectors know about such a diagnosis. As rightly stated, all barriers to testing across all sectors need to be removed. In our medium-sized practice we have identified 11 new people with the HIV infection in the past 6 months giving us a total number of 39 patients with HIV/AIDS. This is a prevalence of almost $0.8 \%$ and twice the expected prevalence for this locality. Of these new patients nine are male, and two are female, the mean age is 38 years and the range is $17-52$ years. The clinicians in the practice have made the diagnosis in three cases: all of the patients now have AIDS. The remaining cases are either newly-registered patients and/or have arrived with a previous HIV diagnosis; two thirds of this latter group are already on highly-active antiretroviral therapy (HAART). We know for a fact that there are at least four more patients in the practice who do not have an official HIV diagnosis but are on HAART (see paragraph below).

Secondly, we still encounter non GUbased hospital practices in the locality which are outdated, bizarre, and just downright silly. For example, four patients we know about have been discharged from the local university-teaching hospital on antiretroviral therapy (HAART) but there is no diagnoses on the discharge summary. When asked for clarification the unit replies by stating 'patient consent has not been given'. Unfortunately, this is this flip-side of 'patient wants'. ${ }^{4}$ How are we expected to provide care for patients when full disclosure has not been possible - for whatever reason? Surely there comes a time when patient-wants are usurped by patient-needs, and let's face it, a more sensible approach to overall care? I have absolutely no doubt that there are other patients who do not divulge information to us for various reasons.

Finally, we recommend that general practices who are remotely interested in this debate should examine the notes of patients found to be HIV-positive to reflect on whether an earlier diagnosis could have been made (be that in primary care or elsewhere for that matter) in a manner which has been reported recently. For example, in one of the cases cited above, the patient had been known to this practice for the previous 4 years, had presented to us with various dermatoses including tinea, had had shingles in the previous year, but had refused to go for HIV-testing despite recommendation on more than one occasion. Could we have done more to make a diagnosis?

\section{Surinder Singh}

Amersham Vale Training Practice, Waldron Health Centre, London SE8 4BG. E-mail: s.singh@pcps.ucl.ac.uk

\section{REFERENCES}

1. Barber TJ, Menon-Johansson A, Barton S. How can we remove barriers to HIV testing outside of a GUM setting? Br J Gen Pract 2008; 58(550): 365.

2. Sudarshi D, Pao D, Murphy G, et al. Missed opportunities for diagnosing primary HIV infection. Sex Transm Infect 2008; 84(1): 14-16.

3. Singh S, Madge S, Theobald N. Missed opportunities for diagnosing primary HIV infection - a response. STI Online, 28 Jan 2008: http://sti.bmj.com/cgi/eletters/ 84/1/14\#665 (accessed 15 Jul 2008).

4. Fernando I, Clutterbuck D. Genitourinary medicine clinic and general practitioner contact: what do patients want? Sex Transm Infect 2008; 84(1): 67-69.

5. Winceslaus SJ, Pinching AP, Harris A, et al. HIV diagnosis: why and how do we miss important clues? Sex Transm Infect 2008; 84(2): 101-102.

\section{Research Ethics Committees}

Trials and Tribulations by Saul Miller ${ }^{1}$ takes the National Research Ethics Service to task for the closure of the Northumberland Research Ethics Committee (REC), but there are compelling reasons behind this decision.

The Northumberland closure is part of a national programme to merge and close NHS RECs because demand for their services is falling. In 2004-2005 there were 153 RECs in England that reviewed 9670 applications. In 2007-2008 the figures were 118 and 7257 respectively. There are many reasons for this change and it is not simply falling research interest. The Northumberland REC latterly has had fewer applications than other local committees and merging it with another will put its members' expertise to better use. It will also save taxpayers' money. While their members selflessly volunteer their time, RECs still have substantial associated costs that come from NHS funds.

The 'triaging' that Miller dislikes is simply an attempt to review, in a rapid and proportionate way, the many minimal risk applications RECs receive. All other research, such as that involving therapy, drugs, mental incapacity, identifiable tissue, personal data, or children, will of course continue to go through a full committee.

\section{Janet Wisely \\ Director, National Patient Safety Agency, \\ National Research Ethics Service, \\ 4-8 Maple Street, London, W1T 5HD. \\ E-mail: janet.wisely@corec.org.uk}

\section{REFERENCE}

1. Miller S. Trials and tribulations. Br J Gen Pract 2008; 58(552): 522.

DOI: 10.3399/bjgp08X319765 